\section{A EDUCAÇÃO SEXUAL NO YOUTUBE: NOTAS SOBRE O CANAL DE JAIRO BOUER}

Pricila Christiane Rodrigues Guimarães [*] Gilson Cruz júnior [**]

[*] Graduada em Informática Educacional pela Universidade Federal do Oeste do Pará (UFOPA) ORCID: https://orcid.org/0000-0003-3415-3518 E-mail: prirodrigues21stm@gmail.com

[**] Doutor em Educação pela Universidade Federal de Santa Catarina (UFSC) - Professor da Universidade Federal do Oeste do Pará (UFOPA) ORCID: https://orcid.org/0000-0003-0743-2247 E-mail: gilsu05@gmail.com

\section{RESUMO}

Este trabalho aborda a dimensão educativa do YouTube, tendo como objetivo investigar o canal do médico Jairo Bouer, com o intuito de analisar seu potencial como veículo de informação sobre a sexualidade. Do ponto de vista metodológico, esta é uma pesquisa qualitativa de natureza descritiva e exploratória. Como resultado, constatou-se que o canal investigado demonstrou relevância social e potencial pedagógico, utilizando-se de diferentes estratégias de interação características dos espaços on-line.

Palavras-chave: YouTube. Educação. Sexualidade. Jairo Bouer. 


\section{INTRODUÇÃO}

Desde a sua gênese, a rede mundial de computadores vem produzindo transformações significativas nos modos como as pessoas acessam, transmitem e processam informações. Trata-se de um recurso que ampliou dramaticamente a agilidade e o alcance dos meios de comunicação incumbidos das referidas tarefas. Essas possibilidades não estão disponíveis apenas para adultos em busca de informações triviais, mas também para jovens e crianças à procura de canais de informação mais discretos nos quais podem obter esclarecimento sobre temas variados: dos banais e corriqueiros aos mais complexos e íntimos.

Um dos exemplos mais apropriados para descrever essa lógica é a sexualidade: problemática que costuma figurar em boa parte das pesquisas realizadas por usuários interessados em preservar seu anonimato. Debater sexo e sexualidade não é tarefa fácil para boa parcela da população, mesmo nas circunstâncias em que esse tipo de tema se revela extremamente necessário, como é o caso da educação familiar. Por conta dessa lacuna, essa responsabilidade finda por recair sobre as escolas, os professores e demais iniciativas de cunho educacional. Ainda assim, boa parte desses profissionais não possui o preparo necessário para lidar com a amálgama de questões inscritas no universo da identidade e diversidade sexual.

Paralelamente, a Internet vem multiplicando as vias de acesso à informação, tornandose uma tecnologia acionada tanto para fins de entretenimento, quanto para propósitos educacionais, como ocorre em situações em que o usuário dedica tempo e atenção a vídeos e demais conteúdos on-line produzidos por especialistas e educadores. Diante disso, a proposta deste trabalho é abordar o canal do médico Jairo Bouer no YouTube, com o intuito de analisar os conteúdos e interações nesse contexto, buscando indícios das aprendizagens relativas à temática da sexualidade e refletindo sobre a natureza pedagógica do canal.

\section{DESENHO METODOLÓGICO}

Esta é uma pesquisa qualitativa de natureza descritiva e exploratória, com foco na Internet como via de acesso a informações sobre sexualidade e também como contexto de aprendizagem. De acordo com Gil (2002, p.41), a pesquisa exploratória busca "proporcionar maior familiaridade com o problema, com vistas a torná-lo mais explícito ou construir hipóteses". Neste caso, o objeto de análise é a rede social YouTube, mais precisamente o 
canal de Jairo Bouer, veículo em que são postados conteúdos audiovisuais a respeito de assuntos diversos no campo da sexualidade. Trata-se de publicações de "domínio público", uma vez que podem ser acessadas gratuita e livremente pela Internet, não sendo necessária a anuência do autor para sua utilização em trabalhos de investigação.

O foco da pesquisa são os vídeos postados por Jairo em seu canal, bem como os aspectos gerais voltados à recepção dos seguidores, que foram observados por meio dos registros deixados por eles. Todos esses conteúdos podem ser entendidos como documentos públicos, que, segundo Laville (1999, p.166), abrangem os "documentos impressos, mas também [...] tudo que se pode extrair dos recursos audiovisuais e, todo vestígio deixado pelo homem". Diante da temática anunciada, foi necessário realizar um breve levantamento bibliográfico, envolvendo pontos como: 1) as relações entre sexualidade e educação; e 2) a origem e as dimensões educativas do YouTube.

O período de investigação foi de 20 de julho a 3 de agosto de 2018. Em termos de empiria, foram selecionados e analisados vídeos postados no canal de Jairo Bouer, bem como as interações deste com seus usuários e seguidores, por meio de comentários ou mesmo de outros vídeos. Em termos de critérios, o aspecto popularidade foi levado em consideração na seleção e análise dos vídeos examinados do canal. Foram escolhidos e assistidos os cinco vídeos mais populares de cada categoria no canal ("Jairo responde", "Collabs do Jairo" e "Curiosidades"). Também foram feitas observações desde as primeiras postagens até as mais recentes, para verificar a evolução do canal.

A avaliação dos dados foi inspirada na análise de conteúdo, abordagem que, de acordo com Gil (2002, p.89), "possibilita a descrição do conteúdo manifesto e latente das comunicações, em que se escolhe o documento, explora o material envolvido, selecionando classificações e unidades e por fim faz-se o tratamento e interpretações dos dados". No total, foram registrados 16 vídeos sobre diversos assuntos que envolviam sexo, saúde e comportamento. No que diz respeito à descrição e análise, optamos por não estabelecer uma separação por categorias, uma vez que o material analisado não favoreceu essa classificação.

\section{SEXUALIDADE E EDUCAÇÃO}

É importante esclarecer que a sexualidade é uma ideia complexa e repleta de nuances. Para Maia e Pastana (2013, p.2), trata-se de um conceito "amplo e abrangente, que se refere 
às manifestações de sentimentos, desejos, atitudes e percepções relacionadas à vida sexual e afetiva, à comunicação e ao vínculo entre as pessoas”. Diferente da crença corrente no senso comum, a sexualidade diz respeito a um amplo conjunto de manifestações que não têm foco somente no sexo. O termo "sexo" alude tanto às diferenças biológicas entre homens e mulheres, quanto às dimensões relativas aos atos e comportamentos sexuais propriamente ditos (MAIA, 2014). Mais do que isso, a sexualidade é um fenômeno plurifacetado que pode se manifestar de diferentes formas em cada indivíduo, variando conforme sua fase de desenvolvimento, de modo que em cada uma delas apresentamos maneiras distintas de expressar os comportamentos no domínio sexual. Nesse conjunto de variáveis, destacam-se o crescimento e o amadurecimento do corpo físico, as práticas sexuais e reprodutivas, a orientação sexual, os vínculos amorosos, entre outros. Além disso, a individualidade no plano da sexualidade também é afetada por fatores como contexto social, familiar, moral e religioso.

Desde a infância, a sexualidade se mostra presente de modo pueril, e com frequência se materializa na forma de gestos sutis de curiosidade. Nessa fase, dúvidas a respeito do próprio corpo e do corpo do outro são comuns, as quais tendem a se expressar de modo pouco influenciado por preconceitos e pudores, uma vez que as crianças ainda não incorporaram plenamente as regras e os protocolos sociais ligados à esfera sexual. Ainda assim,

É importante ressaltar que reconhecer a criança como sexuada não quer dizer que ela expressa a sexualidade genital adulta. Mesmo que ela sinta prazer nesses comportamentos eróticos, ela não o faz de modo adulto, com fantasias sexuais adultas, nem mesmo sob o controle social. Em decorrência disso, observa-se que a maior dificuldade em lidar com as manifestações sexuais na infância ocorre por parte do adulto, que não interpreta a sexualidade nas crianças a partir de suas próprias dificuldades ou não, ou seja, da sua história de educação sexual ao longo da vida (MAIA, 2014, p.5).

Já na idade adulta, a sexualidade passa a abranger aspectos de maior profundidade, como o amadurecimento biológico, psíquico e emocional, além dos cuidados consigo e com o outro, as responsabilidades materna e paterna e os laços matrimoniais/afetivos que regulam os instintos sexuais (desejos, excitação e orgasmo) e impõem maior (auto)controle ao indivíduo, em comparação com o período da adolescência. Mesmo na velhice, quando se intensificam as reduções relativas à libido e ao desempenho sexual, o ser humano ainda não pode ser considerado como plenamente assexuado. Maia (2014, p.4) relata que "ao longo do desenvolvimento humano vamos construindo o sentido da nossa sexualidade, que é 
influenciada pelos padrões culturais e históricos, o processo interpessoal que chamamos de socialização". Desde o momento em que nascemos, nossa sexualidade passa por permanente transformação, ajuste e reajuste, incorporando aspectos elementares dos nossos modos de vida e padrões de conduta. Já Figueiró (2001, p.39, citado por ARAÚJO, 2014, p.13) apresenta um conceito ampliado de sexualidade:

\begin{abstract}
A sexualidade [...] não pode ser restringida à sua dimensão biológica, nem à noção de genitalidade, ou de instinto, ou mesmo de libido. Também não pode ser percebida como uma 'parte' do corpo [...] É uma dimensão "essencialmente humana", cujas significações e vivências são determinadas pela natureza, pela subjetividade de cada ser humano e, sobretudo, pela cultura, que deve ser compreendida em sua totalidade e globalidade, como uma construção social que é condicionada pelos diferentes momentos históricos, econômicos, políticos e sociais (FIGUEIRÓ, 2001, p. 39, citado por ARAÚJO, 2014, p. 12).
\end{abstract}

Diante disso, a educação sexual é apontada como um elemento que auxilia no bemestar individual e no desenvolvimento de uma vida pessoal e sexual saudável. Maia (2008) faz a distinção dos termos educação sexual e orientação sexual, definindo:

\begin{abstract}
[...] por Educação Sexual o processo pelo qual as pessoas formam suas concepções sobre sexualidade em uma cultura e sociedade, desde o nascimento até a morte. Este processo ocorre no cotidiano das relações sociais: biológica, psicológica, social e ética. Quando essa educação ocorre de modo formal, por meio de instruções, chamamos esse processo de Orientação Sexual: aulas, palestras, instrução, informação, o que faz parte da/e na educação sexual, mas não se constitui em si mesma um processo formativo (MAIA, 2008, p. 71).
\end{abstract}

A educação sexual também pode ocorrer de modo informal e não sistematizado, por meio de práticas cotidianas, de discursos familiares, religiosos e midiáticos e de interações diversas. Trata-se de uma modalidade educacional que se difere de seu viés institucionalizado, que ocorre quando há um planejamento prévio e uma intencionalidade pedagógica que norteiam todas as atividades no interior de um dado percurso formativo. Independentemente da natureza do processo educativo, entende-se que o acesso permanente e a consistência dos conteúdos e das experiências educacionais concernidos no campo da sexualidade são elementos essenciais para o êxito dessas iniciativas.

Entre os recursos capazes de contribuir para esse projeto, é possível destacar a proeminência das redes sociais, cuja popularização deve muito ao desenvolvimento e à generalização da Internet, na qualidade de meio que favorece a interação entre usuários de todo o planeta e estabelece laços e comunidades on-line capazes de transcender limites temporais e espaciais. Em vista disso, Pastana e Maia (2016) afirmam que:

Atualmente, o contato com materiais midiáticos é cada vez mais intenso, são cada vez maiores as possibilidades de acesso e o tempo que os adolescentes (e as pessoas 
de forma geral) dedicam a atividades como assistir programas de televisão, vídeos e filmes, escutar músicas, ler revistas e/ou usar a internet para buscar informações, conhecer e conversar com outras pessoas, pesquisar sobre tema de interesse (PASTANA e MAIA, 2006, p. 160).

Por meio dessas e de outras mídias, surgem novas oportunidades de construção de conhecimentos sobre temas diversificados, mesmo os mais obscuros, complexos ou controversos. Nesse contexto, Mattar (2013, p.28) esclarece que as redes sociais adquiriram destaque por conta de sua estreita relação com a Web 2.0: o paradigma da comunicação online voltado ao desenvolvimento de ambientes e espaços virtuais onde o usuário tem à sua disposição recursos que permitem a criação e a partilha de conteúdo, e não apenas o mero consumo e acesso à informação. A categoria "redes sociais" compreende plataformas digitais como Facebook, Instagram e YouTube, domínios nos quais, normalmente, seus usuários se manifestam na forma de perfis pessoais, engajando-se em dinâmicas interacionais específicas e fazendo uso de vídeos, fotos, textos, dentre outros recursos.

\section{YOUTUBE: ORIGEM E POTENCIAL EDUCATIVO}

O YouTube foi criado em 2005, em São Francisco, Califórnia, por Chad Hurley, Steve Chear e Jawed Karin, três ex-funcionários do site de comércio on-line PayPal. A intenção deles era oferecer uma plataforma que permitisse o compartilhamento de vídeos de maneira simples e rápida e que dispensasse conhecimentos especializados (BURGESS; GREEN, 2009). Jawed Karim, um dos cofundadores do YouTube, afirma que o sucesso da plataforma se deu graças à implementação de quatro recursos essenciais, a saber: 1) recomendações de vídeos; 2) compartilhamento de vídeos por meio de links; 3) caixa de comentários em cada vídeo; e 4) um reprodutor de vídeo compatível com outras páginas na Internet. Em 2005, o clipe intitulado Lazy Sunday (Domingo de preguiça) tornou-se o primeiro hit do YouTube, sendo visto 1,2 milhão de vezes em seus dez primeiros dias on-line, e mais de 5 milhões de vezes até fevereiro de 2006. Depois de algum tempo foi retirado do ar junto com mais 500 clipes, por conta da quebra de direitos autorais. Em outubro de 2006, o YouTube foi comprado pela gigante Google por US\$1,65 bilhão. Em novembro de 2007, ele já era o site de entretenimento mais popular do Reino Unido (BURGESS; GREEN, 2009).

O YouTube é uma ferramenta de mídia digital cada vez mais presente no cotidiano de internautas de todo o mundo. Os vídeos e canais mais populares são patrocinados por empresas que, em seu sistema de monetização sustentado por anunciantes, são os 
responsáveis pela receita obtida por administradores e produtores de conteúdo. Sempre que assiste a um vídeo monetizado, o usuário é exposto à publicidade que pode tanto preceder o início do vídeo, quanto estar distribuído em intervalos precisos no meio dele - como uma espécie de comercial.

Burgess e Green (2009, p.45) explicam que "plataformas e tecnologias de novas mídias mais acessíveis podem gerar possibilidades para comercialização de conteúdo amador e, em alguns casos, transformar os produtores desses conteúdos em celebridades". Atualmente, o YouTube é um dos meios pelos quais muitas pessoas "desconhecidas" publicam seus vídeos amadores, que, por vezes, podem se popularizar ou mesmo viralizar na Internet, dando aos criadores de conteúdo "15 minutos de fama" - ou muito mais. O YouTube também é considerado um agregador de conteúdo, uma vez que não produz os conteúdos que os usuários consomem diariamente. Esse protagonismo é assumido por empresas, artistas e pessoas "conhecidas" e "desconhecidas" que alimentam a plataforma com vídeos musicais, de humor e, inclusive, educacionais.

No que diz respeito aos últimos, multiplicam-se as publicações em que são discutidos assuntos variados e com os quais podem ser estabelecidos vínculos de natureza pedagógica, posto que a interação entre produtores e consumidores de conteúdo é necessariamente mediada por algum tipo de informação, opinião ou narrativa. Isso significa que o YouTube pode ser considerado uma espécie de "escola" on-line, com milhares de "professores" e "aulas" no formato audiovisual.

Na perspectiva de Buckingham (2012), as mídias digitais permitem que os estudantes, antes considerados como polos passivos do processo de ensino-aprendizagem, tenham condições de ascender à condição de sujeitos da construção de seu conhecimento. A Web 2.0 preconiza arquiteturas comunicacionais centradas no modelo das mídias sociais, com ênfase em valores como a interatividade e a colaboração, de modo a favorecer processos educacionais que permitam a todos os envolvidos a troca de ideias e experiências de forma coletiva e colaborativa.

O YouTube é uma ferramenta da Web 2.0, e como tal apresenta potencial para atividades educacionais. A interatividade é um fator importante para uma aprendizagem ativa, ainda que os vídeos, por si só, sejam considerados como objetos de aprendizagem de baixa interatividade. Não obstante, o YouTube permite que os usuários se expressem por 
meio de caixas de comentários, que, nesse caso, atuam como recurso participativo voltado à troca de experiências entre diferentes indivíduos. Por acolher uma ampla quantidade de assuntos, a plataforma possui um público massivo e bastante engajado, o que favorece o surgimento de diferentes formas de interlocução, que propiciam oportunidades de aprendizagem menos rígidas, isto é, sem a pressão institucional e a formalidade da sala de aula. Essa dinâmica se manifesta em situações em que um usuário envia uma dúvida a um canal, que, por sua vez, pode efetivar a réplica na forma de um comentário ou até mesmo de um vídeo explicativo, em relação ao qual os demais usuários/seguidores podem explicitar sua concordância e satisfação por meio de "curtidas" e outros comentários. Como afirma Mattar (2013, p.24), “o que está aberto na rede está também mais aberto a críticas”. Deste (e de outros) modo(s), o YouTube atua como um sistema de educação aberta onde todos - usuários registrados ou não - têm acesso a conteúdos e ferramentas que fornecem oportunidades para aprender, produzir e compartilhar.

No YouTube estão disponíveis recursos multimídia gratuitos que podem ser utilizados com finalidades variadas em salas de aulas, multiplicando as formas de interação ao alcance de professores e alunos, permitindo inclusive a sua integração com conteúdos curriculares e objetivos de aprendizagem institucionais. Para Bastos (2011),

[...] o YouTube contém uma série de conteúdos ubíquos e vinculados à realidade, que podem refletir as perguntas, experiências e desejos dos alunos. Por isso, a plataforma torna-se um ambiente de aprendizagem significativo, na medida em que fornece o contexto ou um ponto de partida para uma aprendizagem organizada à volta da solução de problemas autênticos, envolvendo a colaboração, discussão, defesa de ideias e construção de consensos (BASTOS, 2011, p. 40).

A linguagem audiovisual tem o poder de fazer com que as pessoas assimilem informações de forma concreta e contextualizada, além de atingir uma quantidade significativa de receptores, possibilitando a interação entre o on-line e o off-line. Os conteúdos no YouTube também podem levar os internautas a refletir sobre seus próprios comportamentos e atitudes, ao serem sensibilizados por canais e vídeos sobre temas presentes em seu cotidiano. Parte da participação on-line em canais do YouTube é relevante e formativa, o que contribui para o desenvolvimento pessoal dos usuários.

Ao convidar outros especialistas e youtubers para a discussão de assuntos de interesse de seu público, os canais se esforçam para atrair mais atenção para si, por meio de parcerias e alianças entre influenciadores digitais. Barba (2012, p.29) explica que "alguns sites permitem 
que os usuários se organizem em grupos por afinidades e preferências (seguidores), ou cruzem 'canais', coleções de favoritos ou espaços de comunicação dedicados a compartilhar suas experiências com outros". Por meio da plataforma, os usuários podem se manter informados sobre qualquer assunto, logo, ela é uma forma alternativa de aprendizagem.

Dentre os canais do YouTube que promovem debates sobre a temática da sexualidade, destaca-se o trabalho desenvolvido por Jairo Bouer: médico, educador, palestrante, escritor e apresentador de televisão brasileiro. Formado em Psiquiatria pela Faculdade de Medicina da Universidade de São Paulo (FMUSP) e pelo Instituto de Psiquiatria da mesma universidade, Jairo aborda, há anos, temas ligados à sexualidade na TV, no rádio e, mais recentemente, nos meios digitais. Mais especificamente, trabalha com comunicação há 25 anos, focando prevenção, saúde e sexualidade. Já colaborou com veículos como Folha de São Paulo, Rede Globo, MTV, Cultura, Canal Futura, Rádio Jovem Pan, 89 FM, Rádio Metropolitana, entre outros.

Atualmente ele é colunista da Revista Época, do UOL, da CBN e da Rede Atlântida de Rádios (RS e SC). Autor de 11 livros e audiolivros, entre eles "Guia do Sexo" (em parceria com Marcelo Duarte, Panda Books) e "Sexo \& Cia" (Publifolha), Jairo também atua, de forma expressiva, nas mídias digitais com o seu canal no YouTube, sua página do Facebook e seu site pessoal.

Na plataforma em evidência, sua primeira postagem ocorreu em julho de 2016. No vídeo intitulado "Conhecendo o canal Jairo", o médico se apresenta e descreve os objetivos de seu canal: tratar de assuntos envolvendo sexo, saúde e comportamento. De acordo com sua descrição, o canal apresenta uma agenda formal para postagem de vídeos: nas terças-feiras aborda curiosidades e novidades em formato de vlog, e nas quintas-feiras responde a dúvidas enviadas pelos usuários durante a semana, tanto no próprio canal, quanto nas demais mídias sociais.

Por meio dos mecanismos de comunicação via comentários, é possível perceber como as pessoas acompanham, elogiam e interagem com seu trabalho. De acordo com Mattar (2013, p. 110), esse tipo de recurso suporta interatividades essenciais a qualquer ambiente online de aprendizagem. É o que parece ocorrer na relação entre Jairo Bouer e seu público nos seus canais de mídias sociais. Nesse sentido, o médico também disponibiliza seus contatos em outras redes sociais, como Facebook, Twitter, Instagram, Snapchat, além de seu site 
pessoal. Por meio deles, os inscritos e seguidores podem encaminhar dúvidas e sugestões de tema para Jairo, que, por sua vez, pode abordá-los de modo breve (comentários, tweets) ou aprofundado (vídeos e postagens explicativas). Atualmente, o canal de Jairo Bouer no Youtube tem aproximadamente 32 mil inscritos, popularidade significativa quando levamos em consideração o fato de que a sexualidade ainda é uma temática rodeada de tabus.

\section{A EDUCAÇÃO SEXUAL NO CIBERESPAÇO: NOTAS SOBRE O CANAL DE JAIRO BOUER}

Como mencionado, o YouTube é uma plataforma que permite o upload e o compartilhamento de conteúdos audiovisuais. Trata-se de um integrante de destaque da Web 2.0, cenário em que os usuários da rede dispõem de ferramentas acessíveis que dão suporte não apenas ao consumo, mas também à produção e circulação de informações. Segundo a pesquisa Vídeo Viewers 2017, que buscou analisar o comportamento do usuário brasileiro na plataforma, quase 99\% dos internautas consomem vídeos do YouTube. De acordo com a investigação, esse sucesso se justifica por três fatores, que operam de modo coordenado: relevância, aprendizado e tendências.

Quanto à relevância, podemos levar em consideração que, em plataformas digitais de sociabilidade, os usuários têm a oportunidade de buscar conteúdos de acordo com seus próprios interesses. Nesse sentido, o YouTube proporciona um volume crescente de conteúdos que abordam temáticas heterogêneas e se dirigem a todo tipo de público, distinguindo-se dos meios de massa como a TV, cujos canais de comunicação à disposição do espectador não apresentam a mesma abundância e variedade. Já o segundo eixo, o aprendizado, materializa-se em situações nas quais o usuário que não tem domínio de um assunto específico se mostra disposto a recorrer a informações de fácil acesso e com linguagem acessível. Suprida pela plataforma, essa demanda também incita o usuário a interagir com internautas e comunidades on-line que podem disponibilizar recursos complementares àqueles socializados em vídeos e canais de referência. Por fim, no que diz respeito às tendências, o YouTube é um fenômeno de audiência que recorre a métricas de popularidade para dar visibilidade aos conteúdos "em alta" num dado momento, constituindose como um mecanismo essencial no processo de produção e identificação de "virais". Em vista disso, Burgess e Green (2009) esclarecem: 
[...] o YouTube é utilizado de várias maneiras diferentes por cidadãos-consumidores por meio de modelo híbrido de envolvimento com a cultura popular - parte produção amadora, parte consumo criativo. Do ponto de vista da audiência, é uma plataforma que fornece acesso à cultura ou uma plataforma que permite aos seus consumidores atuar como produtores? Essa amplitude é a fonte da diversidade e alcance do YouTube, assim como a causa de muitos choques entre o controle topdown e a emergência bottom-up que produz sua política (BURGESS E GREEN, 2009, p. 32).

Desde a sua origem, o canal de Jairo Bouer passou por diversas mudanças e ajustes. Trata-se de transformações que abrangem aspectos variados: desde a decoração do ambiente de gravação dos vídeos à linguagem verbal e audiovisual utilizada na edição. De modo geral, essas transformações parecem querer diminuir o grau de formalidade do conteúdo produzido, ajudando-o a assumir um caráter cada vez mais leve e descontraído. Da sua criação (2016) às suas postagens mais recentes (2019), percebe-se uma evolução gradual do canal. O cenário, por exemplo, ganhou mais objetos, como um notebook, cuja função não é apenas ornamental. Trata-se de um componente que tenta expressar uma dinâmica de maior interação entre Jairo e os usuários: ao ler os comentários e as dúvidas em seu laptop, eles também aparecerão em tempo real na tela, com o nome e a idade de quem o/a enviou.

É comum que essas transformações sejam percebidas pelos inscritos mais antigos, que, em muitas ocasiões, fazem questão de expressar sua opinião e oferecer feedbacks: "Seus vídeos são ótimos!! Rs” (INSCRITA 1); “Adoro a forma que aborda diversos assuntos com tamanha facilidade sem parecer algo chato e cansativo" (INSCRITA 2); "Gostaria que falasse mais sobre temas relacionados a psiquiatria, pois tenho uma fome de conhecimento quando se trata de entender a complexa mente humana" (INSCRITA 3). Nesse sentido, observa-se que a linguagem (verbal e audiovisual) empregada nos vídeos visa contribuir para o processo de "conquista" de inscritos, que, quando cativados, demonstram estar mais abertos aos conteúdos produzidos e partilhados pelo médico: "Jairo você fala muito bem e adorei suas ideias! Para mim, nos apaixonamos por pessoas, não por gênero ou sexo! E essas suas edições são muito boas!" (INSCRITO 4).

Essas mudanças indicam que o canal vem tentando se adequar ao perfil de seus seguidores, empregando estratégias para cativá-los. Dados da pesquisa "Google e Reds com Consumidores Brasileiros" mostram que, até 2017, 98 milhões de brasileiros acessavam o YouTube pelo menos uma vez por mês. Em sua maioria, esses internautas são jovens e adultos entre 18 e 35 anos. Além disso, demonstram um consumo muito variado: $60 \%$ dos 
que estão acima de 36 anos consomem conteúdos de música, gastronomia, moda e beleza, gaming e futebol. Essa pluralidade também se reflete na crescente representatividade do público: 10\% dos consumidores do YouTube já se declaram LGBT.

Outro aspecto importante é que, levando em consideração o fluxo de usuários e os índices de visualização, observou-se que os conteúdos do canal de Jairo Bouer conseguem abranger não só o seu público formal (os inscritos), mas também usuários que acessam esporadicamente as postagens do influenciador. Um dos exemplos é o vídeo intitulado "Como engrossar o pênis", que atingiu um total de 298 mil visualizações, ultrapassando significativamente a soma de, até então, 31 mil inscritos acumulada pelo canal.

Diferentemente de outros influenciadores digitais que adquirem visibilidade no YouTube, o canal de Jairo Bouer parece alimentar sua base de seguidores com a participação do médico em outros veículos de comunicação. Percebemos, por meio dos comentários dos internautas, o quanto essas aparições em outros veículos são importantes para alimentar a base de seguidores de Jairo: "Acompanho seu trabalho desde o tempo da MTV. Estou adorando seu canal Jairo, parabéns sucesso!!!” (INSCRITA 5); “Conheci o canal agora é já estou adorando!!! Também te acompanho desde a MTV! Sucesso” (INSCRITA 6). Trata-se de um fator que mostra como os meios de comunicação de massa (TV, rádio e mídia impressa) interagem com os meios digitais, garantindo a transferência de público entre diferentes plataformas. Nesse sentido, Jenkins (2009, p.27) relata que "a convergência representa uma transformação cultural, à medida que consumidores são incentivados a procurar novas informações e fazer conexões em meio a conteúdos midiáticos dispersos."

Podemos considerar Jairo Bouer uma figura transmídia, pois está presente tanto na mídia de massa quanto na digital, circulando por plataformas de comunicação e linguagens de diferentes naturezas. De acordo com Jenkins (2009, p.36), "novas tecnologias midiáticas permitiram que o mesmo conteúdo fluísse por vários canais diferentes e assumisse formas distintas no ponto de recepção." É o que se observa em relação à trajetória de Jairo, que começou sua carreira como apresentador na MTV Brasil e hoje aparece em programas de TV tratando sobre assuntos relacionados à sexualidade, dentre eles atrações com alta audiência, como o programa "Encontro com Fátima Bernardes", exibido pela Rede Globo. Apesar de não ter surgido na Internet, como boa parte dos youtubers de sucesso, Jairo consegue se 
manter como figura com relevância crescente na rede, transferindo parte de sua audiência nos meios de massa para o ciberespaço.

Para que os conteúdos possam adquirir maior alcance, os canais no YouTube tendem a utilizar táticas que visam à consolidação de uma base de inscritos. Para isso, faz-se necessário promover adequações não só para a manutenção do público atual, mas também para penetração em novos nichos e segmentos. Burgess e Green (2009) enquadram os canais no Youtube na categoria do reach business ("negócio de alcance"), nos quais os influenciadores lidam com um grande volume de visitantes e uma gama de diferentes audiências.

Uma das maneiras de conseguir isso é mediante a adoção de uma linguagem leve e acessível ao grande público, sobretudo aos mais jovens, que, como vimos, representam a maioria dos usuários na plataforma. No caso do canal do Jairo, essa estratégia pode ser observada no modo como os vídeos postados são editados: entre as falas do médico, costumam ser inseridos memes e trechos de vídeos virais que dialogam com as informações trazidas por ele, deixando-as mais descontraídas. Calixto (2017, p. 2) comenta que "apropriados em larga escala pelos jovens, os memes representam uma das principais expressões narrativas do ciberespaço." Ou seja, atuam como recurso que imprime um maior dinamismo às publicações, tornando-as mais leves e engraçadas.

Há que se destacar que, apesar da menor formalidade, os internautas também percebem tais estratégias como elementos que elevam o grau de didatismo dos vídeos: "Muito bom ver você por aqui no YouTube Dr. Jairo. Sempre acompanhei seu trabalho e uso muito de sua produção em minhas aulas. Parabéns pela iniciativa" (INSCRITO 7). Além de reforçar o potencial instrucional do conteúdo, depoimentos similares evidenciam que o canal do Jairo também é frequentado por professores e educadores que reproduzem esses conteúdos em espaços formais de ensino.

No geral, os temas abordados por Jairo costumam ser selecionados com base nas sugestões do próprio público. Um dos exemplos é o vídeo denominado "Bolinhas no pênis": nele, Jairo explica sobre a existência de algumas bolinhas de cor esbranquiçada na região da glande, deixando suspense sobre a natureza delas, até que, no fim do vídeo, revela que não são decorrentes de nenhuma patologia e que fazem parte da anatomia do pênis. 
O "suspense" criado nesse e em outros vídeos pode estar ligado a uma das métricas mais relevantes do YouTube: a taxa de retenção. De acordo com o canal "Escola para Youtubers", essa taxa corresponde ao cálculo de tempo médio de cada visualização de um vídeo. Por meio desta média, o YouTube elabora um ranking de vídeos, colocando no topo aqueles que conseguem "prender" mais os internautas do começo ao fim, ou pelo maior tempo possível. Trata-se de um indicador objetivo e baseado em cálculos algorítmicos, que busca atuar como parâmetro de qualidade do conteúdo publicado: afinal, para os anunciantes da plataforma são pouco rentáveis os vídeos que não conseguem capturar a atenção dos internautas do início ao fim. Em casos como esse, o conteúdo costuma ser considerado de baixa qualidade ou de reduzido potencial de adesão. Partindo desse entendimento, o mistério feito por Jairo na publicação "Bolinhas no pênis" pode ser interpretado não só como um artifício para adicionar tensão ao conteúdo, mas também como uma maneira de garantir uma taxa de retenção mais elevada, pela via da curiosidade e da distribuição estratégica das informações essenciais ao longo vídeo.

Os internautas também expressam a relevância dos conteúdos do canal como meio de educação complementar em relação à sexualidade. Tendo como referência o vídeo supracitado, observou-se que os internautas reconhecem não só o papel pedagógico do canal, como o empenho em se manter em sintonia com as inquietações do público: "Ufa... Achei que só eu tinha isso [bolinhas brancas]. Cheguei a pensar que fosse uma doença... Parabéns Doutor, seu canal é ótimo, assuntos que eu tenho vergonha de compartilhar com meu pai! Muito bom mesmo!!!" (INSCRITO 8); "Vim correndo pesquisar para ver se isso não era uma doença kkkk valeu." (INSCRITO 9); "Valeu mano já estava a muito tempo procurando na internet tentando me informar se isso era uma doença muito grave, mas agora estou bastante tranquilo em questão disso afinal eu tenho 16 anos e para mim isso é novo ne abraço e mais um inscrito" (INSCRITO 10). Em vista disto, no que diz respeito às aprendizagens sobre a sexualidade e a mídia, Louro (2008) explica:

A construção dos gêneros e das sexualidades dá-se através de inúmeras aprendizagens e práticas, insinua-se nas mais distintas situações, é empreendida de modo explícito ou dissimulado por um conjunto inesgotável de instâncias sociais e culturais. É um processo minucioso, sutil, sempre inacabado. Família, escola, igreja, instituições legais e médicas mantêm-se, por certo, como instâncias importantes nesse processo constitutivo. Por muito tempo, suas orientações e ensinamentos pareceram absolutos, quase soberanos. Mas como esquecer, especialmente na contemporaneidade, a sedução e o impacto da mídia, das novelas e da publicidade, das revistas e da internet, dos sites de relacionamento e dos blogs? Como esquecer o 
cinema e a televisão, os shopping centers ou a música popular? [...] Vivemos mergulhados em seus conselhos e ordens, somos controlados por seus mecanismos, sofremos suas censuras. As proposições e os contornos delineados por essas múltiplas instâncias nem sempre são coerentes ou igualmente autorizados, mas estão, inegavelmente, espalhados por toda a parte e acabam por constituir-se como potentes pedagogias culturais (LOURO, 2008, p.18).

Outro ponto percebido é que os usuários parecem recorrer ao canal mesmo quando se trata de dúvidas teoricamente mais simples. Mais precisamente, trata-se de demandas que indicam, por exemplo, que muitos internautas desconhecem noções básicas de conteúdos que figuram no currículo escolar, como a anatomia humana. No vídeo denominado "Risco de gravidez: dá para engravidar assim?", que faz parte do quadro "Jairo responde", foram constatadas dúvidas como: "Dr, em banheiro público tem risco?! Caso alguém ejacule no acento da privada e uma menina sem perceber sente nele logo depois?! Responde por favor $\wedge \wedge$ canal muito bom.” (INSCRITA 11); "Doutor, e se o garoto estiver com cueca e aqueles calções tactel e a menina nua, ainda assim não tem riscos? Eu estava bem lubrificada e ele esfregava seu órgão contra o meu, mas com essas peças no meio. Obrigada." (INSCRITA 12); "não tem como juliana!" (JAIRO BOUER). Na caixa de comentários do vídeo mencionado, havia muitas outras perguntas similares selecionadas (e respondidas) pelo médico. No seu comentário final, Jairo esclareceu que não é possível engravidar por meio do contato com tampas de privadas ou por cima de roupas, mas somente se houver penetração e ejaculação sem proteção.

No que diz respeito ao fomento de experiências formativas, também são significativas as trocas alinhadas a princípios de colaboração, as quais são frequentemente associadas à noção de inteligências coletivas. Para Levy (2015), esse conceito define:

[...] uma inteligência distribuída por toda parte, incessantemente valorizada, coordenada em tempo real, que resulta em uma mobilização efetiva das competências. Acrescentamos a nossa definição este complemento indispensável: a base e o objetivo da inteligência coletiva são o reconhecimento e o enriquecimento mútuos das pessoas (LEVY, 2015, p. 29).

No caso do YouTube, a aba de comentários de cada vídeo representa o principal modo pelo qual os usuários da plataforma podem promover o intercâmbio de informações e conteúdos. Trata-se de coordenação de esforços com a finalidade de solucionar um problema ou de alcançar um objetivo em comum, que, nesse caso, estão ligados à compreensão geral dos temas abordados pelo canal do Jairo. No vídeo denominado "Como fazer sexo oral com proteção", Jairo responde aos internautas que enviaram dúvidas do tipo: "sexo oral é sexo? E 
quem recebeu sexo oral, também corre riscos, precisa se proteger?”. A partir do comentário postado pelo usuário 29 , outros comentários de resposta foram postados na sequência, dando origem a uma discussão paralela sobre o assunto:

[INSCRITO 29] Sexo oral com preservativo? Isso é horrível. É preferível então descartar o sexo oral das relações íntimas.

[INSCRITO 30] @Inscrito29, Realmente.

[INSCRITA 31] @Inscrito 30, Então é só procurar qualquer uma pra fazer, eu sou uma mulher responsável não faço de forma alguma sem camisinha! Cada conversa...

[INSCRITA 32] Eu tenho curiosidade em saber como é sexo oral com camisinha. Existem camisinhas finas, mas que sejam muito seguras?

[INSCRITA 31] @Inscrito 32, sim, mesmo as camisinhas ultrafinas são seguras, eu faço oral no meu namorado só com camisinha e ele sente prazer assim mesmo.

[INSCRITA 31] Se você ainda assim se recusa a fazer [com] camisinha, tenha uma parceira fixa e faça exames sempre, mas ela terá de confiar em você também. Eu não confio em ninguém, mesmo se eu fosse casada não confiaria, vai saber quando o cara vai decidir te trair...

[INSCRITA 32] @inscrita31, você tem razão. O que não falta é namorados, esposos, traindo as parceiras. Obrigado por comentar.

[INSCRITO 32] @Inscrita31, e você sente prazer quando faz oral com camisinha ou é muito ruim para quem faz mesmo usando camisinha bem fina?

[INSCRITA 31] É um pouco estranho, mas nada que atrapalhe. Eu nunca fiz sem, não posso comparar.

Nesse caso, observa-se que, para os usuários, além dos conhecimentos específicos da área médica, também interessa a experiência "leiga" dos demais internautas em relação aos temas tratados. Além disso, percebe-se a cooperação existente na partilha de informações com o objetivo de ampliar o conhecimento dos pares a respeito do assunto.

A possibilidade de diálogo aberto e seguro sobre sexualidade e temas afins parece ser uma das principais bases da popularidade do canal. A Internet e, mais especificamente, as redes sociais abrem possibilidades de interação anônima, permitindo que as pessoas criem perfis com apelidos não identificáveis ou até mesmo contas fakes. Todas essas possibilidades acabam contribuindo para que a educação relativa à sexualidade ocorra de modo contínuo, por meio de diálogos pessoais ou virtuais. Em vista disso, Rodrigues, Pastana e Maia (2015) esclarecem que a incorporação de conhecimentos sobre a sexualidade:

é um processo contínuo que acontece por toda vida, englobando ações intencionais e não intencionais que ocorrem em diversas instâncias como a família, a escola, os meios de comunicação, instituições legais e médicas, entre outros espaços sociais. Estão envolvidas a aquisição de normas, regras, valores e padrões sobre o sexo e a sexualidade que podem ocorrer de modo explícito ou dissimulado (RODRIGUES, PASTANA E MAIA, 2015, p. 3).

Do ponto da aprendizagem, essa "invisibilidade pública" diminui as chances dos usuários se sentirem intimidados pelo contexto da troca de informações, evitando situações 
de constrangimento e exposição. Trata-se de um aspecto significativo, principalmente para os adolescentes, o público que mais costuma nutrir dúvidas sobre a sexualidade e que muitas vezes pode não dispor de meios para esclarecê-las com os pais e demais familiares, haja vista que a educação sexual ainda representa um tema tabu em muitos cenários.

Sob a ótica educacional, um dos aparentes desafios de canais similares ao de Jairo é a indissociabilidade de sua função educacional e informativa em relação ao imperativo da expansão da base de inscritos. Entende-se que essa dinâmica, quando não equilibrada, pode gerar atritos e inclusive a sobreposição de estratégias de entretenimento e atração de público ao conteúdo "sério" do canal, podendo tornar o último menos consistente e pedagógico. Em contrapartida, em situações de harmonia entre educação e entretenimento, abre-se a possibilidade da divulgação de informação juntamente com elementos estilísticos caros à cultura digital, como humor, narrativas e modos de comunicação menos formais, os quais costumam ser mais eficazes a públicos mais amplos. Este pode ser considerado um cenário ideal, já que a informação "pura", por si só, nem sempre é suficiente para geração de audiência e popularidade.

Em seu canal, Jairo aborda temas que vão do campo médico e das ciências da saúde, como Infecções Sexualmente Transmissíveis (ISTs) e seus sintomas, a questões de ordem sociocultural, como é o caso do vídeo "Tamanho do pênis". Neste, o médico problematiza as razões que levam a população, sobretudo os homens, a se preocupar com as proporções da genitália masculina. Segundo Moran (2013, p.28), "aprendemos pelo interesse, pela necessidade. Aprendemos mais facilmente quando percebemos o objetivo, a utilidade de algo, quando isso nos traz vantagens." Ao dialogar com o imaginário social, Jairo abre caminhos para uma troca de informações baseada em questões de relevo para seus seguidores.

Outra estratégia utilizada por Jairo Bouer para ampliação da base de inscritos é a realização de vídeos com outros youtubers. Um dos exemplos desse esforço é o quadro denominado "Jairo Collab", no qual o médico discute temas de seu canal com convidados que, em sua maioria, são "personalidades" com fama equivalente ou maior que a de Jairo. No vídeo intitulado "O passado da mina", Jairo discute como as mulheres evoluíram e acumularam diversas conquistas, enquanto alguns homens se sentem desorientados em meio ao contexto de empoderamento feminino. Nessa ocasião, ele contou com a presença de Ed e Léo, donos do canal denominado "Manual do homem moderno", que dá dicas sobre 
relacionamentos, sexo, desenvolvimento pessoal e moda para homens. Trata-se de um canal que possui uma soma considerável de inscritos: pouco mais de 1 milhão de seguidores.

Em geral, a lógica das parcerias serve como estratégia para uma espécie de intercâmbio de seguidores entre dois ou mais canais ou influenciadores. Trata-se da possibilidade de aumentar uma dada base de inscritos por meio de uma outra base pertencente a convidados e parceiros, que, no canal de Jairo Bouer, figuram no quadro Collab. Do ponto de vista educacional, essa manobra exige cautela na escolha do assunto a ser discutido, pois ele deve ser compatível com o escopo temático dos canais envolvidos para que o conteúdo mantenha relevância para os seguidores de ambas as partes, garantindo, assim, o sucesso na "transferência" de inscritos. Em relação a esse intercâmbio, Moran (2013, p. 143) dá indícios de que a condição para o sucesso desse tipo de tática é justamente a garantia de inteligibilidade do conteúdo para diferentes públicos: "a variação de estratégias responde também pela necessidade de respeitar os ritmos diferentes de aprendizagem de cada aprendiz. Nem todos aprendem do mesmo modo, no mesmo ritmo e ao mesmo tempo."

O collab realizado com Ed e Léo teve 10.728 visualizações, contando com a participação de um público majoritariamente masculino, além de pontos de vista diversificados e opiniões divergentes em torno do assunto. Dentre as participações mais relevantes do público, constam as manifestações masculinas que reconhecem as desigualdades entre homens e mulheres, bem como as posturas masculinas dignas de crítica e problematização:

Muito interessante o vídeo, creio que todo homem já passou ou, infelizmente, ainda passa por esse "dilema". Porém, mais interessante ainda, é ver que a maioria dos comentários neste vídeo refletem exatamente a linha de pensamento que está sendo criticada, sendo que o comentário mais curtido, no momento em que escrevo, insinua que o homem que concorda com o que é dito no vídeo é 'corno'. Em tempos onde alguns debatem a futilidade dos conteúdos mais consumidos no YouTube, e o uso intensivo deste site pelo público jovem, pergunto-me se as pessoas que comentam aqui, e se escondem atrás de avatares falsos, representam esse público. $\mathrm{Ou}$ seja, são crianças e adolescentes iniciando seus relacionamentos e ainda mantendo essa cultura patriarcal. Isso sem mencionar os tantos outros que comentaram e parecem ser adultos jovens. Não poderia haver demonstração maior de que este vídeo, este debate, é extremamente necessário em nossa sociedade e, em si mesmo, parte da solução questionada por um dos integrantes do "Homem Moderno". Por fim, concordo com o ponto de vista do [ANÕNIMO]: aceitar a ideia de igualdade de gênero não implica em aceitar toda uma gama de comportamentos. É possível aceitar que mulheres tenham vida sexual muito ativa, com vários parceiros ao longo da vida, mas não querer isso para sua companheira porque você (homem, principalmente) não quer isso para você. A partir do momento que você pode, é falta de bom senso, para dizer o mínimo, alegar que outro alguém não possa porque é do gênero $\mathrm{x}$, da cor $\mathrm{y}$ ou da preferência $\mathrm{z}$. Além disso, se você não 
concorda, apresente argumentos ao debate, não fique simplesmente empacando a foda alheia (INSCRITO 13).

Constatou-se também que houve avaliações positivas do vídeo por parte do público feminino, que procurou endossar a participação dos homens que compartilharam uma autocrítica a partir do debate promovido pelo Jairo Collab. Dentre a mulheres que participaram da discussão do vídeo, destacam-se as seguidoras que compartilham relatos pessoais que não apenas dão visibilidade às questões problematizadas no vídeo de Jairo, mas também ilustram modos de vida que afrontam diretamente a moral patriarcal posta em xeque no debate empreendido.

Gente, cada um tem que cuidar da sua vida, se você Homem quer se casar com uma mulher virgem e pura, se case com uma freira simples assim, mas fique sabendo que toda pessoa que se casa virgem depois de alguns anos de casamento sente vontade de recuperar o tempo perdido, de viver tudo que não viveu, eu conheço várias mulheres e homens virgens que depois de anos acabaram traindo o companheiro (a) então não se iludam, vocês serão cornos querendo ou não, se você pegar uma mulher rodada a chance de ser corno é muito baixa, porque ela já deu tudo que tinha que dar e vai aquietar o faixo, a mesma coisa acontece com o homem galinha, depois de comer todo tipo de mulher ele escolhe uma pra casar e aquieta o faixo. Eu sou rodada e vivo muito feliz namorando serio há 3 anos, tenho um relacionamento aberto e não vivo nessa hipocrisia de vocês, na minha relação não existe machismo, direitos são iguais, e tem um monte de homem dando em cima de mim querendo namorar comigo mesmo sabendo que tenho namorado, mas eu não dou a mínima, tenho respeito pelo meu companheiro, os homens que são machistas são tudo falso moralista, se casam com mulher virgem pra trair elas sem camisinha com prostituta e passar doença pra coitada, não valem nada, e vocês devem gostar de criança ne? Porque para encontrar uma mulher maior de idade e virgem hoje em dia só se for freira eu quero é distância desses pedófilos, tenho nojo de vocês. E todo homem machista, ou é velho feio, ou tem pinto pequeno ou é ruim de cama, as rodadas que não querem vocês, deixa para virgens otárias para casarem e serem Amélias e pegarem doenças da amante de vocês kkkkkk (INSCRITA 15).

De todos os collabs realizados pelo canal, esse é o que possui mais comentários: aproximadamente 150. Foram apresentadas duas opiniões, uma masculina e uma feminina, nas quais se percebe um debate acerca do comportamento das mulheres da atualidade, bem como o machismo cristalizado na cultura e nas posturas masculinas. Moran (2013, p.50) explica que a partilha de vivências e histórias é um dos principais aspectos educativos da cultura digital: "a relação com a mídia eletrônica é prazerosa - ninguém obriga que ela ocorra; é uma relação feita por meio da sedução, da emoção, da exploração sensorial, da narrativa. Aprendemos vendo as histórias dos outros e as histórias que os outros nos contam'. O quadro Collabs, por meio dos diversos temas apresentados, demonstrou um potencial pedagógico ao permitir que os internautas, em um espaço de sociabilidade, partilhem opiniões, experiências e relatos que servem ora de exemplo e inspiração, ora de 
objeto de crítica e problematização. Em ambos os casos há sempre a probabilidade de troca de informação e construção de conhecimento a partir de depoimentos pessoais, em que são reportadas tanto "lições" sobre temas específicos, quanto relatos de mudanças de pontos de vista no tocante à esfera da sexualidade.

\section{CONSIDERAÇÕES FINAIS}

O objetivo deste trabalho foi investigar o canal do médico Jairo Bouer averiguando seus conteúdos com intuito de refletir sobre seu potencial como meio de informação sobre a sexualidade. Por meio do processo de análise, percebeu-se que os vídeos apresentados e discutidos abordavam temáticas diversas do campo demarcado e que seu conteúdo informativo permite, em muitos casos, considerá-los materiais com elevado potencial didático. Do mesmo modo, ao propiciar ferramentas para a distribuição de conteúdos audiovisuais, além de permitir a interação e troca de informações entre usuários, o YouTube também se qualifica como plataforma de ensino-aprendizagem colaborativa.

Por meio dos comentários dos internautas, observou-se que boa parte dos inscritos e seguidores do canal do Jairo Bouer é composta por jovens e adolescentes, fase em que os indivíduos normalmente iniciam sua vida sexual e por isso tendem a apresentar dúvidas e curiosidades a esse respeito. Do ponto de vista educacional, é possível dizer que uma das principais potências do canal consiste em sua abordagem menos formal de temas complexos e delicados, oferecendo uma rede aberta de fácil acesso, constituída por conteúdos produzidos por um profissional-especialista (Jairo), além de contexto seguro para o compartilhamento de histórias e experiências. Com isso, demonstra a sua capacidade de ensejar a construção de conhecimentos por meio do consumo de conteúdos audiovisuais e da partilha suas vivências pessoais - e por vezes íntimas.

Para exercer seu papel pedagógico, o canal do Jairo com frequência define sua pauta com base nas demandas e interesses do público, permitindo que as discussões sejam iniciadas no plano do senso comum e aprofundadas com saberes científicos e especializados. Com isso, mostra-se capaz de diluir preconceitos e tabus existentes acerca da sexualidade, ao se constituir como um espaço que, apesar de público e aberto, também propicia interações anônimas e sigilosas, diminuindo o grau de exposição e os riscos de constrangimento por parte daqueles em busca de esclarecimento. 
Por fim, acredita-se que trabalhos futuros possam explorar com maiores detalhes aspectos não abordados nessa pesquisa, a exemplo dos demais canais do Youtube dirigidos ao universo da sexualidade e que se propõem a abordar o tema fora da tônica medicalizada que ainda prevalece nos discursos e nas prescrições a esse respeito dentro e fora da internet. A despeito de sua abordagem "amigável" e heterodoxa, Jairo também pertence ao campo da medicina, com frequência se valendo do poder e da autoridade conferida pela área. Esse argumento sinaliza a necessidade de deslocar o foco para influenciadores digitais/youtubers com filiações e perfis outros, bem como as possíveis nuances presentes nos conhecimentos produzidos sobre a sexualidade em cada uma dessas perspectivas.

\section{REFERÊNCIAS}

ARAUJO, K. C. V. Sexualidade na internet: Análise de blog sobre sexualidade e educação sexual. Dissertação (Mestrado em Educação Escolar), UNESP/Araraquara, 2014.

BARBA, C. Computadores em sala de aula: métodos e usos. Porto Alegre: Penso, 2012.

BASTOS, M. da A. A. O Youtube e o pensamento de Ordem Superior em Inglês (LE): um estudo com alunos do ensino secundário. Dissertação (Mestrado em Estudo de Crianças), Universidade do Minho, 2011.

BOUER, J. Gazeta Digital Jairo Bouer responde. Domingo, 13 de agosto de 2006. Disponível em: $\quad<$ http://www.gazetadigital.com.br/suplementos/zine/jairo-bouerresponde/118604>. Acessado em 30 de maio de 2018.

BUCKINGHAM, David. Cultura Digital, Educação Midiática e o lugar da escolarização. Educação e realidade. Porto alegre, v. 35, n. 3, p. 37-58, 2012.

BURGESS, J.; GREEN J. Youtube e a Revolução Digital: como maior fenômeno da cultura participativa transformou a mídia e a sociedade. São Paulo: Aleph, 2009.

CALIXTO, D. de O. Memes na Internet: entrelaçamentos entre Educomunicação, cibercultura e a 'zoiera' de estudantes nas redes sociais. Dissertação (Mestrado em Ciências da Comunicação), Universidade de São Paulo, 2017.

GIL, A. C. Como elaborar projetos de pesquisa. São Paulo: Atlas, 2002. 
JENKINS, H. Cultura da convergência. São Paulo: Aleph, 2009.

LAVILLE, C. A construção do saber: manual de metodologia de pesquisa em ciências humanas. Porto Alegre: Artmed; Belo Horizonte: Editora UFMG, 1999.

LÉVY, P. A inteligência coletiva: por uma antropologia do ciberespaço. São Paulo: Edições Loyola, 2015.

LOURO, G. L. Gênero e sexualidade: pedagogias contemporâneas. Pró-Posições, Campinas, v.19, n. 2, p.17-23, maio/ago, 2008.

MAIA, A. C. B. A educação sexual repressiva padrões definidores de normalidade. In: SOUZA, C. B. G.; RIBEIRO, P. R. M. (Orgs.). Sexualidade, diversidade e culturas escolares: contribuições ibero-americanas para estudos de educação, gênero e valores. Araraquara: UNESP; Universidad de Alcalá, p. 67-83, 2008.

MAIA, A. C. B.; PASTANA, M. Sexualidade, Gênero e Mídia: Projeto educação sexual com estudantes de comunicação e psicologia. Araraquara: UNESP-Bauru, 2013.

MAIA, A. C. B. Sexualidade e educação sexual. Araraquara: UNESP-Bauru, 2014.

MATTAR, J. Web 2.0 e redes sociais na educação. São Paulo: Artesanato Educacional, 2013.

MORAN, J. M. Ensino e aprendizagem inovadores com tecnologias audiovisuais e telemáticas. In: MORAN, J. M.; MASSETTO, M. T.; BEHRENS, M. A. (Orgs.) et al. Novas tecnologias e mediação pedagógica. Campinas, SP: Papirus, 2013.

PASTANA, M.; MAIA, A. C. B. Diálogo sobre sexualidade e mídia com adolescentes: possibilidades de atividades e discussões. UNESP-Araraquara; Bauru, 2016.

RODRIGUES, G.; PASTANA, M.; MAIA, A. C. B. A sexualidade nos meios de comunicação: concepções de estudantes de jornalismo. In: IV Simpósio Internacional de Educação Sexual: Feminismos, identidades de gênero e políticas públicas, Maringá, Anais... Maringá: UEM, 2015. 


\section{EDUCACIÓN SEXUAL EN YOUTUBE: NOTAS SOBRE EL CANAL DE JAIRO BOUER}

\section{Resumen}

Este artículo aborda la dimensión educativa de YouTube, con el objetivo de investigar el canal del doctor Jairo Bouer, analizando su potencial como vehículo para la información sobre sexualidad. Desde el punto de vista metodológico, constituye una investigación cualitativa de carácter descriptivo y exploratorio. Como resultado, señala que el canal investigado demostró relevancia social y potencial pedagógico, utilizando diferentes estrategias de interacción características de los espacios en línea.

Palabras claves: YouTube, Educación, Sexualidad, Jairo Bouer.

\section{SEX EDUCATION ON YOUTUBE: NOTES ON JAIRO BOUER'S CHANNEL}

\section{Abstract}

This paper addresses the educational dimension of YouTube, aiming to investigate doctor Jairo Bouer channel, analyzing its potential as a vehicle for information about sexuality. From the methodological point of view, it constitutes a qualitative research of a descriptive and exploratory nature. As a result, it notes that the channel investigated demonstrated social relevance and pedagogical potential, using different interaction strategies characteristic of online spaces.

Key-words: YouTube, Education, Sexuality, Jairo Bouer.

Submetido em: Agosto de 2019.

Aprovado em: Dezembro de 2019.

Publicado em: Dezembro de 2019. 